\title{
Evaluation of Skin Allografts from Massive Weight Loss Donors in Major Burn Treatment
}

\author{
YASMIN E. MOHAMED, M.B.B.Ch.*; MOHAMED S. BADAWY, M.D.*; MANAL H. MOUSA, M.D.**; \\ SOHA F. ELMEKKAWY, M.D.* and AHMED M. ELBADAWY, M.D.*
}

The Department of Plastic, Burn and Maxillofacial Surgery* and Histology Department**, Faculty of Medicine, Ain Shams University, Cairo, Egypt

\begin{abstract}
Background: The main stay for treatment of major burns is early excision and coverage. Nevertheless, the skin autografts is the gold standard for coverage but in major burns, the donor for autografts is limited. So, normal skin substitutes are considered as an advantageous alternative. Although they are limited due to their cost and availability. Skin allografts are a rich source which was considered as a medical waste and thanks to bariatric surgery which assisted obese patients to lose weight leaving them in a need for different body contouring procedure.
\end{abstract}

So, this study aimed to evaluate the pathological and clinical effects of skin Allografts from Massive Weight Loss donors to treat major burn.

Patients and Methods: A total of 80 patients with major burns underwent early excision in (early $48 \mathrm{hrs}$. post trauma) and covered by either: Allografts from MWL donors (in group I) or by: Non MWL Allografts (group II). Biopsies were taken and examined for the effect of allografts over the wound bed and the Photographic Wound Assessment Tool (PWAT) was applied to evaluate the percentage of improvement after applying different types of skin substitutes.

Results: Percentage of improvement was significantly higher among patients who used Allografts from non-massive weight loss donors when compared with patients who used Allografts from massive weight loss donors.

Conclusion: Non MWL allografts are of better results in the take of the $1^{\text {st }}$ dressing change and in the detachment day. Moreover, patients who received Allografts from MWL developed sepsis that increased their hospital stay and hence more complications. Yet, MWL donors are a reliable source for allografts until cadaveric skin donation is legalized especially in major burns treatment as the donor is not always sufficient for coverage so, the use of skin Allografts is a lifesaving alternative.

Key Words: Skin Allografts - Massive Weight Loss - Major Burns - Burn wound.

\section{INTRODUCTION}

Major burn traumas are associated with increased mortalities as a result of the systemic effect of the toxic eschar that promotes an upregulation of inflammatory mediators and proapoptotic factors [1].
As a result, management of major burns always demands early excision of the necrotic eschar, usually in the first 24 to 72 hours. The raw areas left after excision should be covered immediately to decrease morbidities and mortalities. The gold standard for coverage is the split thickness autografts from healthy skin [2].

However, in major burns, an adequate donor of skin autografts is not always available. So, skin allografts are considered a life-saving alternative. As, Allografts decrease wound pain, lower bacterial count, and provide dermal matrix elements which can persist and improve final graft properties and scarring after definitive autografting [3].

It also possesses many positive characteristics, such as adherence, elasticity, competent of bacterial barrier, prevents desiccation of bone and tendon [4]. On the other hand, obesity rates have continued to rise and hence bariatric surgery lifted behind a special entity of massive wight loss (MWL) patients who lose $50 \%$ or greater loss of their excess weight with a resultant characteristic morphologic, functional, and pathologic skin effects [5].

Furthermore, in MWL patients there is an increased rate of excisional procedures done for body lifting as Abdominoplasty, Thigh lift, Mastopexy and Brachioplasty.

These surgical excisional procedures are considered a rich source for skin donation especially for patients with major burns. So, it deserves to be studied meticulously from its applicability to its pathological and clinical effects.

\section{PATIENTS AND METHODS}

Between September 2020 and March 2021, 80 patients with major burns in Burn Center Attached to Plastic, Burn and Maxillofacial Department. Ain Shams University. Patients were divided into 
2 groups: Group I received Allograft from MWL donors and Group II received Allografts from non MWL donors.

\section{Harvesting of allografts:}

Allografts were harvested in the operative room immediately after Allograft excision. A separate table is set for allograft harvest covered with sterilized towels and prepared with (Watson Modified humpy knife, Kocher forceps, and surgical blade). The Allograft is harvested using Watson modified humby knife with a cutting depth of 0.015 inches, while maintaining the same sterile conditions of the original operation.

The Allograft then, wrapped in a sterile gauze soaked with saline and preserved in a sterile container with physiologic saline and antibiotics (cefazolin $1 \mathrm{~g}$ and gentamicin $1 \mathrm{~g}$ ) then, container was marked and labelled with the name, data of the donor, date of harvesting and expiry date. In this step, the Allograft can be used immediately or stored in the refrigerator at $4^{\circ} \mathrm{C}$ for maximum 10 days.

The donor of the Allografts, were patients who underwent aesthetic excisional procedures. Either MWL patients who lost $50 \%$ of their weight, or Normal donors who seek body contouring procedures without significant weight loss. Aesthetic excisional procedures such as abdominoplasty, breast reductions, thigh lift and Brachioplasty.

Recipient bed was prepared by tangential excision after $48 \mathrm{hrs}$. of trauma and if the excision was adequate and there is sufficient donor for skin Autografting, a skin autograft will be used. The remaining wound will be covered using either Allografts from MWL in group I or allografts from non MWL in group II.

For all groups wound was assessed using the photographic wound assessment tool (PWAT) giving the wound two scores initial and final. Then, the percentage of improvement was calculated, and multiple biopsies were taken from the wound: Biopsy 1: After the application of the Allograft, 4- quadrant incisional biopsies including a fullthickness skin and the underlying wound bed at the $7^{\text {th }}$ post-operative day (under sedation) to study the effect of allografts on burn wound. Biopsy 2: Biopsy at the $21^{\text {st }}$ day to study the fate of the allografts either adherent or detached, 4-quadrant Incisional biopsies including a full-thickness skin and the underlying wound bed Detached Allograft was scored using the Banff Working Classification of Skin Containing Composite Tissue Allograft Pathology [6].

\section{RESULTS}

The detachment day of the allografts from the burn wound show significant $p$-values between group I and II in group I skin allografts detached earlier than that the Allografts in group II.

There was statistically significant difference found between the two groups regarding Hospital stay, the highest value was among group I patients (50-70) 62 \pm 12 with $p$-value (0.003).

Number of patients who developed sepsis was higher among group I in relation to number of patients who developed sepsis in group II.

In this study, 40 donors were biopsied and histologically examined before the application of the allografts on the burn wound. $45 \%$ of the biopsied skin showed collagen arrangement in strict parallel fashion, at right angles to stretching forces and diminished elastin fibers as a result of MWL. 15\% showed atypical cells with vacuolated cytoplasm with deeply stained nuclei as a result to aging and obesity. Finally, $40 \%$ showed collagen fibers organized in a mesh-like structure and elastin fibers from a horizontal arrangement in the deep dermis to a more vertical arrangement.

Photographic analysis: The results provided by the PWAT showed a statistically significant difference found between the two groups regarding Percentage of improvement, with significant $p$ values: (0.000, and 0.023) respectively. (Table 1$)$.

Table (1): A table shows the $p$-value between Group I (no. =40), Group II (no. = 40) regarding Photographic Wound Assessment Tool (PWAT) Initial Score, Final Score and Percentage of improvement.

\begin{tabular}{|c|c|c|c|c|c|}
\hline $\begin{array}{l}\text { Photographic Wound Assessment } \\
\text { T-Tool PWAT }\end{array}$ & $\begin{array}{l}\text { Group I } \\
\text { No. }=40\end{array}$ & $\begin{array}{l}\text { Group II } \\
\text { No. }=40\end{array}$ & $\begin{array}{c}\text { Test } \\
\text { value }\end{array}$ & $\begin{array}{c}p- \\
\text { value }\end{array}$ & Sig. \\
\hline $\begin{array}{l}\text { Initial score: } \\
\text { Mean } \pm \mathrm{SD} \\
\text { Range }\end{array}$ & $\begin{array}{l}15.50 \pm 1.43 \\
13-17\end{array}$ & $\begin{array}{l}14.35 \pm 1.29 \\
13-16\end{array}$ & $11.032 •$ & 0.000 & HS \\
\hline $\begin{array}{l}\text { Final score: } \\
\text { Mean } \pm \mathrm{SD} \\
\text { Range }\end{array}$ & $\begin{array}{l}13.98 \pm 1.46 \\
11-15\end{array}$ & $\begin{array}{l}12.70 \pm 1.64 \\
10-14\end{array}$ & $30.168 \bullet$ & 0.000 & HS \\
\hline $\begin{array}{l}\text { Percentage of improvement: } \\
\text { Median (IQR) } \\
\text { Range }\end{array}$ & $\begin{array}{l}13.30(6.6-18) \\
6.2-26.6\end{array}$ & $\begin{array}{l}9.75(7-21) \\
7-37\end{array}$ & $7.582 \neq$ & 0.023 & $\mathrm{~S}$ \\
\hline
\end{tabular}


The percentage of the improvement of the burn wound of the 2 groups showed significant p-values as in group I mean \pm SD 13.98 \pm 1.46 and group II $12.70 \pm 1.64$.

The statistically significant difference found between the two groups in regard to the Percentage of improvement, the highest percentages were among group II. This indicated that the effect of the non MWL Allografts is better than the MWL ones on the burn wound as a temporary dressing according to the Photographic Wound Assessment Tool (PWAT).

Histological analysis: The Allograft after (either from Group I or II) the $1^{\text {st }}$ dressing change showed signs of take between the graft and the wound bed seen as increased number of capillaries and granulation tissue and collagen matrix organization. (Fig. 1).

Detachment of the Allograft in the $21^{\text {st }}$ day with $2^{\text {nd }}$ biopsy was examined according to Banff

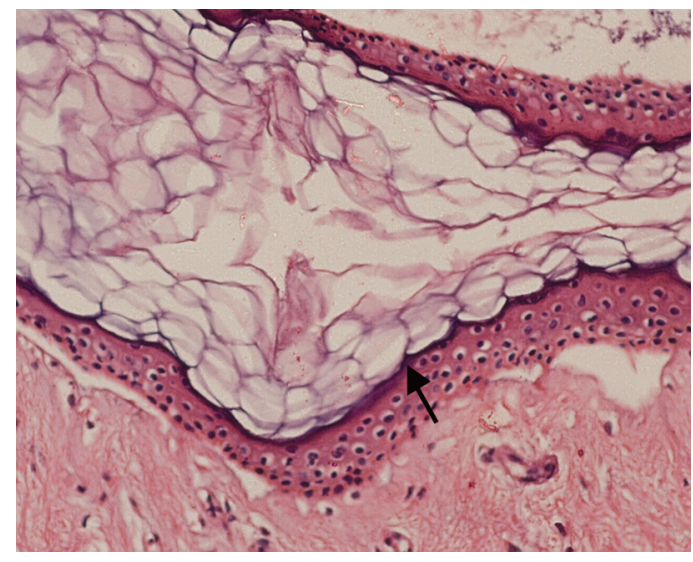

Fig. (1): A slide shows the signs of adherence between the Allograft and the wound bed seen as increased capillaries, granulation tissues and collagen matrix organization. (H\&E x100).

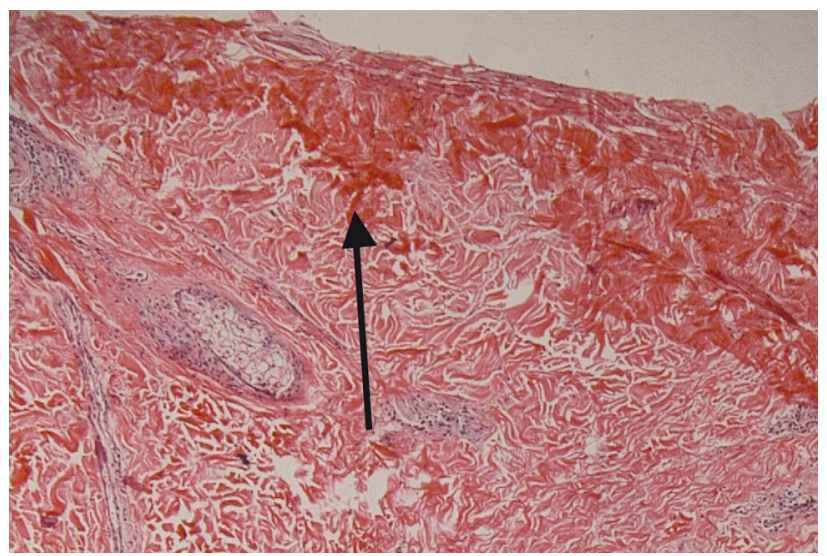

Fig. (3): A slide shows Grade I rejection between non MWL Allograft and the wound bed (Group II) as less lymphocytic perivascular infiltration with no involvement of the underlying epidermis. (H\&E x100).
Working Classification of Skin Containing Composite Tissue Allograft, in the 14th day Allografts from MWL (Group I) showed Grade 1 rejection as mild dermal lymphocytic perivascular infiltration with no involvement of the underlying epidermis. (Fig. 2).

The Allograft from non MWL donor (Group II) also showed similar signs to those in Group I in the $14^{\text {th }}$, but they were less severe as showed less lymphocytic infiltration. (Fig. 3).

The full detachment of the Allograft was histologically demonstrated as Grade III rejection. Rejection seen as severe inflammation, with epidermal involvement (epithelial apoptosis and keratinolysis). It consists of a dense lymphocytic infiltrate forming nodules around the capillaries of the upper dermis, and the larger blood vessels of the mid and lower dermis. There was no difference between both groups. (Fig. 4).

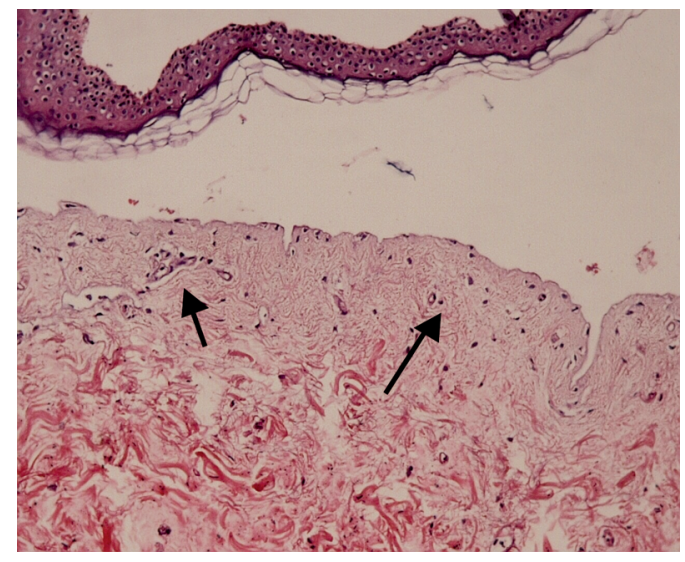

Fig. (2): A slide shows Grade I rejection between the MWL Allograft and the wound bed (Group I) seen as mild dermal lymphocytic perivascular infiltration with no involvement of the underlying epidermis. (H\&E $\mathrm{x} 100)$.

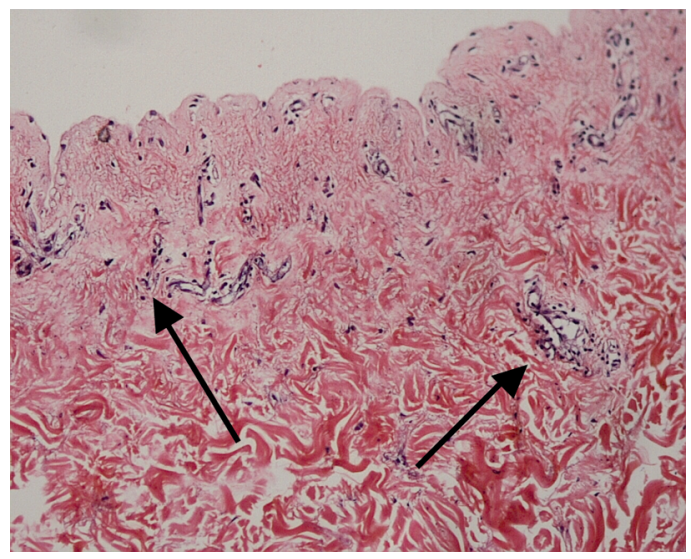

Fig. (4): A slide shows Grade III rejection as it indicates the full detachment of the Allografts from the burn wound. (H\&E x100). 


\section{DISCUSSION}

Burn injuries one of the most widespread form of trauma around the globe, and it accounts for 80,000 and 100,000 of burn victims every year in Egypt [7].

Major burn are burns exceeding 25\% TBSA or burns that involve face, hands, perineum, genitals, or burns crossing a major joint [8], accounts for the highest incidence of morbidities and mortalities between all types of burns.

Moreover, the mainstay for major burn management is early excision as it decreases the toxins released into the blood stream reducing the possibility of developing sepsis and more importantly, death. It also exposes a viable bed for coverage.

The exact time for early excision is yet in a great deal of controversy, but in the current study, we timed the early excision once the patient is fully resuscitated; therefore, it took place on the $3^{\text {rd }}$ day post injury.

Delayed wound excision causes not only significantly more wound bacterial contamination, but also a higher incidence of invasive wound infection than that seen with early excision.

Coverage of the burn wound after excision is the goal in major burn treatment, Autograft makes the best and the gold standard coverage. However in major burns, an adequate amount of skin autografts is not always available. So, the skin allografts are considered as a life-saving alternative [9].

Today, allografts are widely used to achieve temporary biologic coverage in major burns as Fletcher et al., [10] demonstrated in their study. And that turns to its ability to adhere to the wound bed. It also lowers the bacterial loads in contaminated wound. Plus, it is cost effective, particularly when compared to synthetic dressings, which makes it the gold standard temporary dressing in major burns as found by Paggiaro et al., [11].

Different types of Skin substitutes were developed as an alternative to autografts and most of them are limited due to their cost. On the other hand, cadaveric skin donation is not yet official in many countries including Egypt, so, the available and cheap alternative is the skin excised in different body contouring procedures which were previously considered as medical waste. Especially from patients who have lost massive amounts of weight.
MWL is defined by Shrivastava et al., [12] as $50 \%$ or more loss of the excess weight and they are most often bothered by the excess skin in areas of the lower abdomen, breast, axilla, buttocks upper arms, and thighs, making them a good source of allograft donation.

Yet, the effect of this skin Allografts on burn wound is not previously discussed and hence the main objective of the study.

These results were comparable with Yosipovitch et al., [13] which found that Skin quality is impaired in MWL patients with poor wound collagen deposition, which might be due to adipose tissue structural changes and as the process of MWL itself creates damage in the extracellular matrix [14]. And Allografts harvested from non MWL patient showed only changes related to aging. Yet the structural integrity of the skin was preserved [15].

Skin allograft rejection or detachment is the recipient's immune response following recognition of alloantigens leading to cellular destruction and loss of the Allograft [16].

In a study done by Rezaei et al., [17] they found that rejection of the skin allograft is considered inevitable, and it is likely to occur within two weeks.

The statistically significant difference found between Group I \& Group II regarding the day the Allograft detached from the burn wound (Detachment Day) were significant as in group I (MWL) skin allografts detached earlier than the Allografts in group II (non MWL) and there was highly statistically significant difference found between group I and II regarding the take of the Allograft in the $1^{\text {st }}$ dressing change.

\section{Conclusion:}

Non MWL allografts are of better results in the take of the $1^{\text {st }}$ dressing change and in the detachment day. Moreover, patients who received Allografts from MWL developed sepsis that increased their hospital stay and hence more complications. Yet, MWL donors are a reliable source for allografts until cadaveric skin donation is legalized. Especially in Major burns treatment as the donor is not always sufficient so, the use of skin Allografts is a lifesaving alternative.

\section{REFERENCES}

1- Nielson C.B., Duethman N.C., Howard J.M., Moncure M. and Wood J.G.: Burns: Pathophysiology of systemic complications and current management. Journal of Burn Care \& Research, Jan. 1; 38 (1): e469-81, 2017. 
2- Choi M. and Panthaki Z.J.: Tangential excision of burn wounds. Journal of Craniofacial Surgery, Jul. 1;19 (4): 1056-60, 2008

3- Cleland H., Wasiak J., Dobson H., Paul M., Pratt G., Paul E., Herson M. and Akbarzadeh S.: Clinical application and viability of cryopreserved cadaveric skin allografts in severe burn: A retrospective analysis. Burns, Feb. 1; 40 (1): 61-6, 2014.

4- Snyder R.J.: Treatment of nonhealing ulcers with allografts. Clinics in Dermatology, Jul. 1; 23 (4): 388-95, 2005.

5- Stark B. and Felmerer G.: Plastic Surgery after Massive Weight Loss. In Principles of Metabolic Surgery (pp. 367380). Springer, Berlin, Heidelberg, 2012.

6- Cendales L.C., Kanitakis J., Schneeberger S., Burns C., Ruiz P., Landin L., Remmelink M., Hewitt C.W., Landgren T., Lyons B. and Drachenberg C.B.: The Banff 2007 working classification of skin-containing composite tissue allograft pathology. American Journal of Transplantation, Jul. 8 (7): 1396-400, 2008.

7- WHO, World Bank, United Nations. Factsheet: World Report on Disability 2011. Inj. Prev. [Internet], 14 (1): 2, 2011.

8- Rowan M.P., Cancio L.C., Elster E.A., Burmeister D.M., Rose L.F., Natesan S., Chan R.K., Christy R.J. and Chung K.K.: Burn wound healing and treatment: Review and advancements. Critical Care, Dec. 19 (1): 1-2, 2015.

9- Gideroğlu K., Yaman M., Tunçay E., Taşdelen I, Kaşıç̧ı Ö.H., Filinte G.T.: Use of Close Relative (Family) Skin Allograft in Major Burns, 27 (3): 205-9, 2017.

10- Fletcher J.L., Caterson E.J., Hale R.G., Cancio L.C., Renz E.M. and Chan R.K.: Characterization of skin allograft use in thermal injury. Journal of Burn Care \& Research, Jan. 1; 34 (1): 168-75, 2013.
11- Paggiaro A.O., Bastianelli R., Carvalho V.F., Isaac C. and Gemperli R.: Is allograft skin, the gold-standard for burn skin substitute? A systematic literature review and metaanalysis. Journal of Plastic, Reconstructive \& Aesthetic Surgery, Aug. 1; 72 (8): 1245-53, 2019.

12- Shrivastava P., Aditya A. and Kumar K.R.: Body contouring surgery in a massive weight loss patient: An overview. Indian Journal of Plastic Surgery, Oct. 41 (S 01): 114-29, 2008.

13- Yosipovitch G., DeVore A. and Dawn A.: Obesity and the skin: skin physiology and skin manifestations of obesity. Journal of the American Academy of Dermatology, Jun. 1; 56 (6): 901-16, 2007.

14- Choo S., Marti G., Nastai M., Mallalieu J. and Shermak M.A.: Biomechanical properties of skin in massive weight loss patients. Obesity Surgery, Oct. 20 (10): 1422-8, 2010.

15- Mahdavi-Mazdeh M., Heshmati B.N., Tavakoli S.A., Ayaz M., Ardalan F.A. and Momeni M.: Human split-thickness skin allograft: Skin substitute in the treatment of burn. International Journal of Organ Transplantation Medicine, 4 (3): 96, 2013.

16- Dixit S., Baganizi D.R., Sahu R., Dosunmu E., Chaudhari A., Vig K., Pillai S.R., Singh S.R. and Dennis V.A.: Immunological challenges associated with artificial skin grafts: Available solutions and stem cells in future design of synthetic skin. Journal of Biological Engineering, Dec. 11 (1): 1-23, 2017.

17- Rezaei E., Beiraghi-Toosi A., Ahmadabadi A., Tavousi S.H., Tabrizi A.A., Fotuhi K., Nooghabi M.J., Manafi A. and Moghadam S.A.: Can skin allograft occasionally act as a permanent coverage in deep burns? A pilot study. World Journal of Plastic Surgery, Jan. 6 (1): 94, 2017. 